\title{
Endovascular Management of Intracranial Dural AVFs: Principles
}

(D).D. Bhatia, (D) H. Lee, (D). Kortman, (D). Klostranec, (D)W. Guest, (D)T. Wälchli, (DI. Radovanovic, (D)T. Krings, and (D).M. Pereira

\section{ABSTRACT}

SUMMARY: Intracranial dural AVFs are abnormal communications between arteries that supply the dura mater and draining cortical veins or venous sinuses. They are believed to form as a response to venous insults such as thrombosis, trauma, or infection. Classification and management are dependent on the presence of drainage/reflux into cortical veins because such drainage markedly elevates the risk of hemorrhage or venous congestion, resulting in neurologic deficits. AVFs with tolerable symptoms and benign drainage patterns can be managed conservatively. Intolerable symptoms, presentation with hemorrhage/neurologic deficits, or aggressive drainage patterns are indications for intervention. Treatment options include microsurgical disconnection, endovascular transarterial embolization, transvenous embolization, or a combination. This is the first in a series of 3 articles on endovascular management of intracranial dural AVFs, in which we outline the principles and outcomes of endovascular treatment.

ABBREVIATIONS: dAVF = dural AVF; ECA = external carotid artery; GKRS = gamma knife radiosurgery; TA $=$ transarterial; TV $=$ transvenous

$\mathbf{T}$ his is the first in a series of 3 articles on the endovascular management of intracranial dural AVFs (dAVFs) based on our experience in treating these lesions during the past 25 years at Toronto Western Hospital. In this introductory article, we outline the epidemiology, classification, diagnosis, and management principles. In the following 2 articles, we detail the principles of transarterial and transvenous embolization, respectively.

\section{Definition}

Intracranial dAVFs are abnormal direct vascular communications between arteries that supply the dura mater and draining cortical veins or dural venous sinuses, without a normal intervening capillary network. ${ }^{1-3}$

Arterial supply may be composed of a single feeder or multiple feeders. ${ }^{1,2}$ The supplying arteries most often originate external

Received February 2, 2021; accepted after revision July 7.

From the Divisions of Neuroradiology (K.D.B., H.L., H.K., J.K., W.G., T.K., V.M.P.) and Neurosurgery (T.W., I.R., T.K., V.M.P.), Toronto Western Hospital, Toronto, Ontario, Canada; Department of Medical Imaging (K.D.B.), Sydney Children's Hospital Network, Westmead, New South Wales, Australia; Division of Paediatrics (K.D.B.), Faculty of Medicine, University of Sydney, Camperdown, New South Wales, Australia; Division of Paediatrics (K.D.B.), Faculty of Medicine, University of New South Wales, Kensington, New South Wales, Australia; and Division of Medical Imaging (K.D.B.), Faculty of Medicine, Macquarie University, Macquarie Park, New South Wales, Australia.

Please address correspondence to Kartik Dev Bhatia, MD, Department of Medical Imaging, Sydney Children's Hospital Network, Corner Hawkesbury Rd and Hainsworth St, Westmead, NSW, 2145, Australia; e-mail: kartikdevbhatia@gmail.com

- Indicates open access to non-subscribers at www.ajnr.org

http://dx.doi.org/10.3174/ajnr.A7304 to the dura mater (eg, the middle meningeal artery arising from the internal maxillary artery) ${ }^{1}$ but can less commonly arise from intradural pial artery branches, which are known to supply dural structures (eg, the artery of Davidoff and Schechter arising from the posterior cerebral artery and supplying the inferior medial tentorium). ${ }^{4-7}$ Secondary induced pial supply from vessels that do not normally supply the dura is well-described in the literature; ${ }^{4}$ however, if these vessels are the sole arterial supply, the lesion is, by definition, a pial vascular malformation rather than a dAVF. ${ }^{1,4}$

Venous drainage can be directly into cortical veins, directly into the dural venous sinuses, or into dural venous sinuses with reflux into the cortical veins. ${ }^{2,3,8}$ Possible arterial supply and venous drainage patterns are demonstrated in Fig 1.

\section{Epidemiology}

Intracranial dAVFs are rare lesions with a detection rate of $<1$ per 100,000 persons in any given year across a variety of populations (0.16-0.51). ${ }^{9-11}$ Clinical presentation is most often between 50 and 70 years of age, and there is a mild female predominance (female/male ratio, 11:9). ${ }^{9-12}$ dAVFs represent approximately $10 \%-15 \%$ of all intracranial vascular malformations. ${ }^{1,9,13}$ The most common locations (in descending order) are the transversesigmoid sinus, cavernous sinus, and tentorium. . $^{211,12,14}$

Intracranial hemorrhage is the initial clinical presentation in $12 \%-18 \%$ of cases. ${ }^{2,11,12,14}$ Risk factors for hemorrhagic presentation (in descending order of risk) include previous hemorrhage, cortical venous reflux, cortical venous ectasia, location (craniocervical 


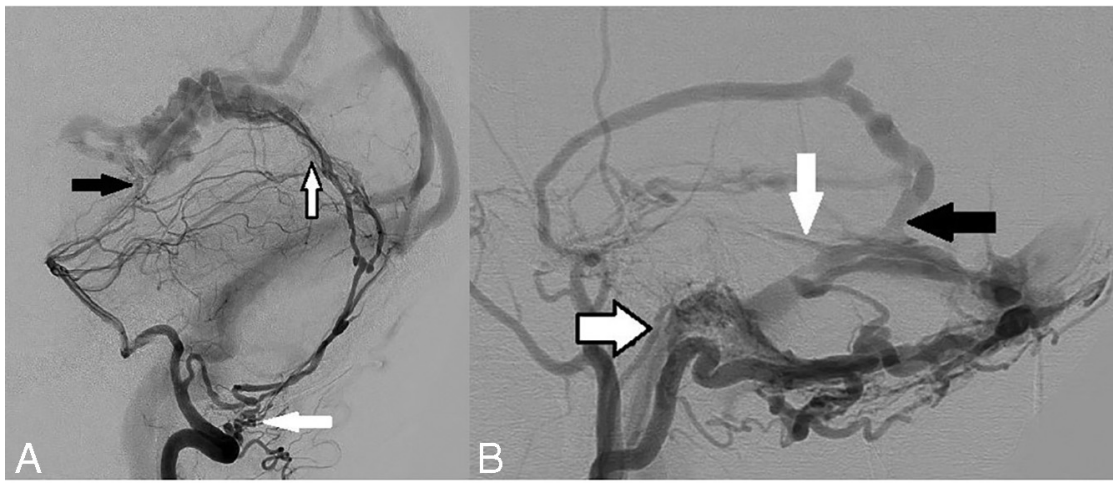

FIG 1. Arterial supply and venous drainage patterns in dAVFs. A, Arterial supply: Left vertebral artery angiogram in a lateral projection shows a falcotentorial dAVF with all 3 different forms of arterial supply: 1) extradural origin of a dural artery: left posterior meningeal artery arising from the extracranial distal V3 segment of the left vertebral artery (white arrow) and providing posterior supply to the fistula via the artery of the falx cerebelli; 2) intradural origin of a dural artery: Artery of Davidoff and Schechter arising from the P1-2 junction of the left posterior cerebral artery, traveling along the free edge of the tentorium cerebelli and supplying the AVF from its undersurface (black arrow); 3) secondary-induced pial artery supply: several small, irregular, induced pial branches from the distal aspect of the left superior cerebellar artery supplying the posterior aspect of the fistula (black border arrow). Reproduced from Bhatia $\mathrm{K}$ et al. ${ }^{7} \mathrm{~B}$, Venous drainage: Left external carotid artery angiogram in a lateral projection in a patient with multiple intracranial dAVFs demonstrates different patterns of venous drainage. A large left transverse sinus fistula is present with supply from an enlarged squamous temporal branch of the middle meningeal artery and draining directly into the transverse sinus (black arrow). There is sinus reflux of contrast into the torcula (Cognard Ila) and cortical venous reflux into the vein of Labbe (white arrow, Cognard Ilb). This is a Cognard Ila +b AVF. A left condylar fistula is also present with arterial supply from the jugular branch of the left ascending pharyngeal artery (black border arrow) and draining directly into a condylar vein (direct cortical venous drainage). This is a Cognard III AVF.

Aggressive venous drainage is characterized by cortical venous reflux (Borden II, Cognard IIb) or direct cortical venous drainage \pm ectasia (Borden III, Cognard III-IV). An aggressive venographic pattern strongly correlates with and predicts the occurrence of intracranial hemorrhage and nonhemorrhagic neurologic deficits. $^{2,3,8}$ These venous drainage patterns are demonstrated in Fig $1 B$.

In addition to the above classification schemes based on the presence of venous reflux, dAVFs can also be classified on the basis of their anatomic location and the embryologic epidural compartment into which they drain. The Lasjaunias-Geibprasert classification system was proposed in 2008, dividing cranial and spinal dAVFs into 3 embryologically determined epidural drainage compartments (ventral, dorsal, and lateral epidural types). ${ }^{18}$ Each of these drainage patterns are associated with differing sex distributions, rates of cortical venous reflux, and clinical presentations (benign versus aggressive). ${ }^{18}$ The utility of this classification system is the ability to understand the anatomicembryologic basis for the aggressive

junction, tentorium, transverse-sigmoid sinus, anterior cranial fossa, superior sagittal sinus), and male sex..$^{2,8,12}$ Nonhemorrhagic neurologic deficits (including focal deficits, encephalopathy, and seizures) represent $12 \%-20 \%$ of clinical presentations and are also associated with cortical venous reflux and intracranial venous hypertension. ${ }^{8,12,14}$ Direct cortical venous drainage, cortical venous reflux, and hemorrhagic presentation are more common in men. ${ }^{2,8}$

The pathogenesis of dural AVFs is debated, but pathology involving the intracranial venous system appears to play a central role. ${ }^{13}$ Such pathology can include prothrombotic disorders and hormonal states predisposing to venous sinus occlusion (including pregnancy), previous cranial surgery, trauma, chronic venous hypertension, and infection such as mastoiditis adjacent to the sigmoid sinus. ${ }^{15,16}$ Venous sinus thrombosis with venous hypertension is thought to promote formation of dural AVFs via ischemia-related angiogenesis. ${ }^{17}$

\section{Classification}

Both Cognard et $\mathrm{al}^{2}$ and Borden et $\mathrm{al}^{3}$ demonstrated that the natural history of dAVFs was related to the pattern of venous drainage, and this was the basis for their respective classification systems. In both classification systems, dAVFs can be broadly divided into benign (Borden I, Cognard I-IIa) and aggressive (Borden II-III, Cognard IIb-V) patterns of venous drainage (Table). ${ }^{2,3}$ Benign venous drainage is characterized by drainage into the dural venous sinuses without cortical venous reflux. behavior of a dAVF and to help predict the natural history based on location. Therefore, it does not replace the important Borden or Cognard systems, but rather provides additional information.

Ventral epidural drainage (eg, basiocciput, sigmoid sinus) involves drainage toward the extracranial ventral venous plexuses, is more common in women, and has a more benign presentation. Dorsal epidural drainage (eg, transverse sinus, superior sagittal sinus) typically involves drainage into dural venous sinuses. Lateral epidural drainage (eg, petrous, ethmoid, falcotentorial junction) is the most aggressive group due to drainage directly into cortical veins. ${ }^{18}$ These lateral epidural locations are more commonly affected in men. ${ }^{12,19,20}$ Therefore, the higher rate of hemorrhagic presentation in men may be explained by the relatively sex-specific anatomic distribution of dAVFs and aggressive venous drainage patterns seen in the lateral epidural group. ${ }^{2,8,18}$

\section{Natural History}

In benign dAVFs (Borden I, Cognard I-IIa), Gross and Du, ${ }^{8}$ in 2012, demonstrated no intracranial hemorrhages or new neurologic deficits during 409 lesion-years of follow-up. This was consistent with the original findings of Cognard et al, ${ }^{2}$ in 1995, who reported nonaggressive clinical presentations in 83 of 84 patients with type I dAVFs and no intracranial hemorrhages in 111 patients with type I-IIa dAVFs. Asymptomatic or minimally 


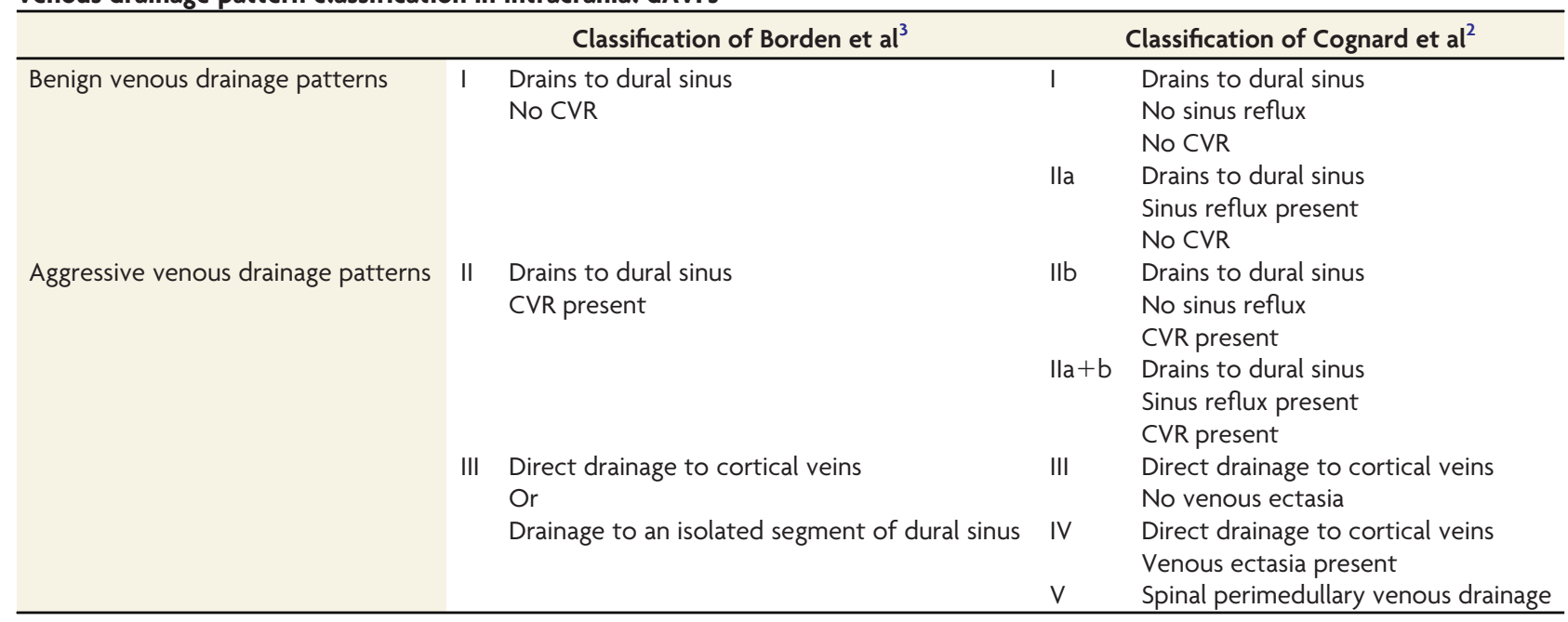

Note:-CVR indicates cortical venous reflux.

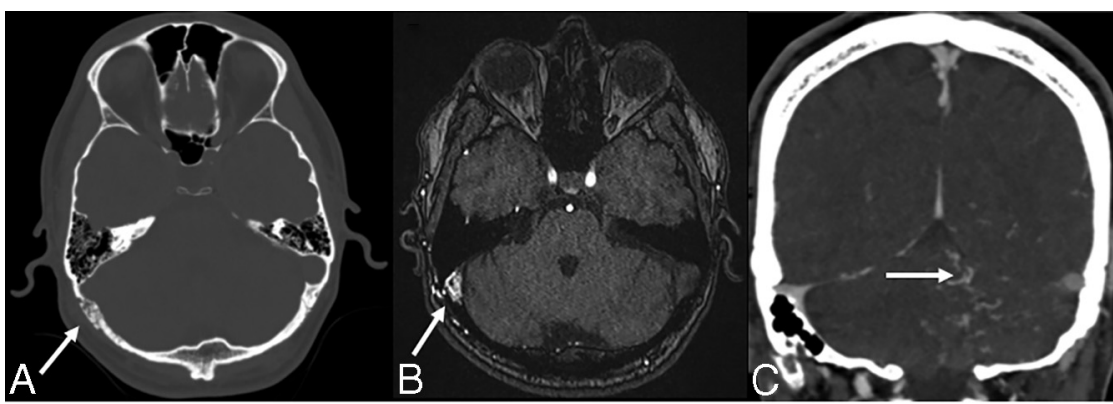

FIG 2. Noninvasive imaging characteristics of dAVFs. A, Axial bone window noncontrast CT image of a patient with a right transverse-sigmoid sinus dAVF demonstrates enlarged right retromastoid transosseous vascular channels from occipital artery feeders (white arrow). B, Axial TOF-MRA image in the same patient demonstrates abnormal hyperintense signal in the right transverse-sigmoid sinus junction (white arrow) due to arterialization of the sinus, with adjacent asymmetrically enlarged occipital artery feeders. C, Coronal contrast-enhanced CT image in a patient with a left transverse sinus dAVF demonstrates enlarged tortuous pial veins over the left cerebellum (white arrow), resulting from cortical venous reflux.

symptomatic patients, regardless of classification status, have a low annual hemorrhage risk of $2 \%{ }^{8}$

On the other hand, the odds ratio of intracranial hemorrhage in patients with cortical venous reflux is $17.5 .^{12}$ The Toronto Brain Vascular Malformation Study Group previously reported clinical outcomes in untreated or undertreated patients with cortical venous reflux, identifying an annual nonhemorrhagic neurologic deficit rate of $6.9 \%$, an annual hemorrhage rate of $8.1 \%$, an annual mortality rate of $10.4 \%$, and a total annual event rate of $15 \%{ }^{21}$

Studies on the natural history of dAVFs stratified by venous drainage patterns report annual hemorrhage rates of $6 \%$ with cortical venous reflux, $10 \%$ with direct cortical venous drainage, and $21 \%$ with cortical venous ectasia. ${ }^{8}$ A nonhemorrhagic neurologic deficit at initial presentation is associated with a $10 \%$ annual hemorrhage rate and an initial hemorrhagic presentation with a $46 \%$ future annual hemorrhage rate. ${ }^{8}$ The highest risk period for rebleeding is within the first 2 weeks after the initial hemorrhage (up to $35 \%$ ), ${ }^{22}$ suggesting that these patients should be treated more acutely.

\section{Diagnosis}

Consideration of a diagnosis of $\mathrm{dAVF}$ may be based initially on the clinical presentation and noncontrast imaging findings. Clinical presentations of nonhemorrhagic dAVFs include pulsatile tinnitus (particularly for lesions adjacent to the petrous bone or transverse-sigmoid sinus), ${ }^{23}$ chemosis and proptosis (for carotid cavernous fistulas due to congestion of the ophthalmic veins), ${ }^{24}$ progressive early-onset dementia (due to congestion of the deep venous system of the diencephalon and striatum), ${ }^{25}$ and seizures (due to congestion of the superficial venous system of the cortex). ${ }^{2}$ A background history of dural venous sinus thrombosis, intracranial infection, cranial surgery, or head trauma may also be suggestive. ${ }^{13}$ Hemorrhagic presentation is typically with sudden onset of severe headache, seizures, focal neurologic deficits, or loss of consciousness. ${ }^{13}$

Noncontrast Imaging. Noncontrast imaging findings suggestive of a nonhemorrhagic dAVF include serpiginous dilated cortical veins (mildly hyperattenuating on noncontrast $\mathrm{CT}$, hypointense T2/FLAIR flow voids on MR imaging), vasogenic edema secondary to venous congestion, and dilated transosseous vascular channels (particularly in the temporal and occipital bones) best appreciated on the bone window settings of CT imaging (Fig $2 A){ }^{26,27}$ This latter finding is also useful to distinguish a pial vascular malformation from a dAVF (because only the latter would be supplied by enlarged transosseous arterial vessels). ${ }^{27}$

Clinical presentation of nonhemorrhagic dAVFs with seizures is typically associated with superficial venous congestion, which, on noninvasive imaging, is characterized by vasogenic edema in the subcortical white matter and enlarged T2 FLAIR serpiginous flow voids over the cerebral convexities. ${ }^{2}$ Clinical presentation 
with dementia is typically associated with deep venous congestion, characterized by edema in the thalami/basal ganglia, as well as ventriculomegaly. ${ }^{25}$ Pulsatile tinnitus as a presenting symptom usually indicates proximity of the fistula to the petrous temporal bone or sigmoid sinus and is seen with fistulas involving the transverse-sigmoid sinuses, petrous ridge, or hypoglossal canal. ${ }^{23}$ Proptosis and chemosis, usually associated with carotid cavernous dAVFs, will typically manifest on imaging with enlarged superior ophthalmic veins. ${ }^{24}$

Noncontrast imaging findings in hemorrhagic dAVFs can include subdural, subarachnoid, intraparenchymal, and/or intraventricular hemorrhage. ${ }^{28}$ A particularly suggestive finding is the combination of subdural and intraparenchymal hemorrhage; this pattern occurs most commonly with traumatic brain injury; but outside the setting of trauma, it should raise suspicion of a dAVF. ${ }^{28-30}$ Aneurysmal or parenchymal AVMs related to hemorrhage may involve the intraparenchymal and subarachnoid spaces but usually do not rupture the arachnoid mater to enter the subdural space. ${ }^{28}$ In dAVFs, however, enlarged cortical veins traverse the subarachnoid and subdural spaces; thus, venous rupture can be associated with this otherwise uncommon pattern outside the setting of trauma. ${ }^{29,30}$

TOF-MRA is a useful initial vascular imaging technique for detection of high-flow dAVFs. ${ }^{31}$ The typical suppression of caudally directed venous flow undertaken to acquire TOF-MRA without venous contamination is useful in detecting abnormal early venous filling as a result of dAVFs. ${ }^{32}$ High-flow AVFs, as a result of transmission of intravascular protons that have undergone excitation in a caudal section directly into cortical veins or dural venous sinuses, can thus result in abnormal hyperintense signal within intracranial venous structures. ${ }^{33}$ Examples of this are demonstrated in Figs $2 B$ and $3 D$.

Contrast-Enhanced Noninvasive Imaging. CT angiography and gadolinium-enhanced MR angiography are useful in demonstrating early venous filling in dAVFs but require precise timing of image acquisition relative to the administration of the contrast bolus to ensure that venous enhancement is truly a result of arteriovenous shunting rather than venous contamination from late timing. ${ }^{34}$ A classic imaging finding in carotid cavernous fistulas is asymmetric cavernous sinus enhancement on CT angiography, often in association with enlargement of the superior ophthalmic vein. ${ }^{35}$ Contrast-enhanced CT and MR imaging are also both useful for demonstrating venous congestion and indirect evidence of cortical venous reflux, characterized by enlarged tortuous pial veins over the cerebral or cerebellar convexities (Fig 2C). The presence of venous congestion and cortical venous reflux would also be supported by ipsilateral white matter vasogenic edema and enlarged serpiginous surface vessels on precontrast CT or T2 FLAIR sequences.

Time-resolved gadolinium-enhanced MR angiography is a particularly useful noninvasive imaging tool for the characterization of dAVFs because it allows assessment of the contrast bolus in multiple phases. ${ }^{36}$ The use of $4 \mathrm{D}$ CTA is also increasing for this diagnostic purpose. ${ }^{37}$

DSA. Ultimately, DSA is the criterion standard for the diagnosis and assessment of dAVFs. ${ }^{38}$ In our practice, we use 6-vessel cerebral angiography, including assessment of the upper neck and facial structures within the FOV as appropriate, to ensure identification of all the important arterial feeders to the AVF and to fully appreciate the venous drainage pattern and impact on the venous drainage of the normal brain parenchyma. In addition, we use a magnified high-frame-rate (typically 6 frames per second) DSA centered on the fistulous point to fully understand the angioanatomy, architecture, and flow dynamics of the fistula. The use of $3 \mathrm{D}$ rotational angiography with reconstruction of the volumetric acquisition in multiple planes (essentially creating a conebeam CTA with intra-arterial injection), timed to demonstrate the arterial feeders and the venous drainage pathway, allows detailed assessment of all arterial feeders and their relationship to the skull base foramina. ${ }^{39}$ A sample case involving the facial arcade is demonstrated in Fig 3.

These additional techniques allow us to identify external carotid artery (ECA)-ICA anastomoses and cranial nerve arterial supplies that may be at risk during endovascular treatment and thus reduce our treatment-related risk profile. Selective injection of the ascending pharyngeal artery, occipital artery, and/or the internal maxillary artery is often useful (in combination with selective $3 \mathrm{D}$ rotational angiography) to demonstrate important arterial feeders that may not be appreciated when there is shunting across multiple other arterial supply points. ${ }^{40}$ An example of the utility of such selective injection is for identification of the facial nerve arterial arcade (in particular the petrous branch of the middle meningeal artery) via internal maxillary or middle meningeal artery injection for assessment of petrous AVFs, ${ }^{41}$ in which there are often multiple competing occipital artery feeders obscuring the arcade on more proximal ECA injections. The utility of $3 \mathrm{D}$ rotational angiography is demonstrated in Fig $3 B,-C$.

\section{Management}

Our management of dAVFs is guided by 2 main principles:

1. Detailed anatomic assessment (based on DSA findings)

2. Multidisciplinary discussion.

Detailed Anatomic Assessment. We undertake detailed anatomic assessment of the DSA imaging (including 3D rotational angiography with MPRs) to assist in management decision-making via a 4-step process:

1. Benign vs aggressive: We determine whether the AVF is angiographically benign or aggressive on the basis of the absence or presence of cortical venous reflux/drainage.

2. Arterial supply and venous drainage: We determine all visible arterial supplies to the AVF, the location of the fistulous point, and the primary venous drainage points. Cure of the AVF via embolization will be dependent on successful occlusion of the fistulous point and the foot of the draining vein.

3. Risk from a transarterial (TA) embolization approach: Based on the arterial supply, we determine the risk of cranial nerve palsy or potential embolization across ECA-ICA anastomoses that would be associated with a TA embolization approach (eg, an AVF supplied primarily by branches of the neuromeningeal division of the ascending pharyngeal artery would pose a high risk of cranial nerve IX, X, and XII palsy via a transarterial 


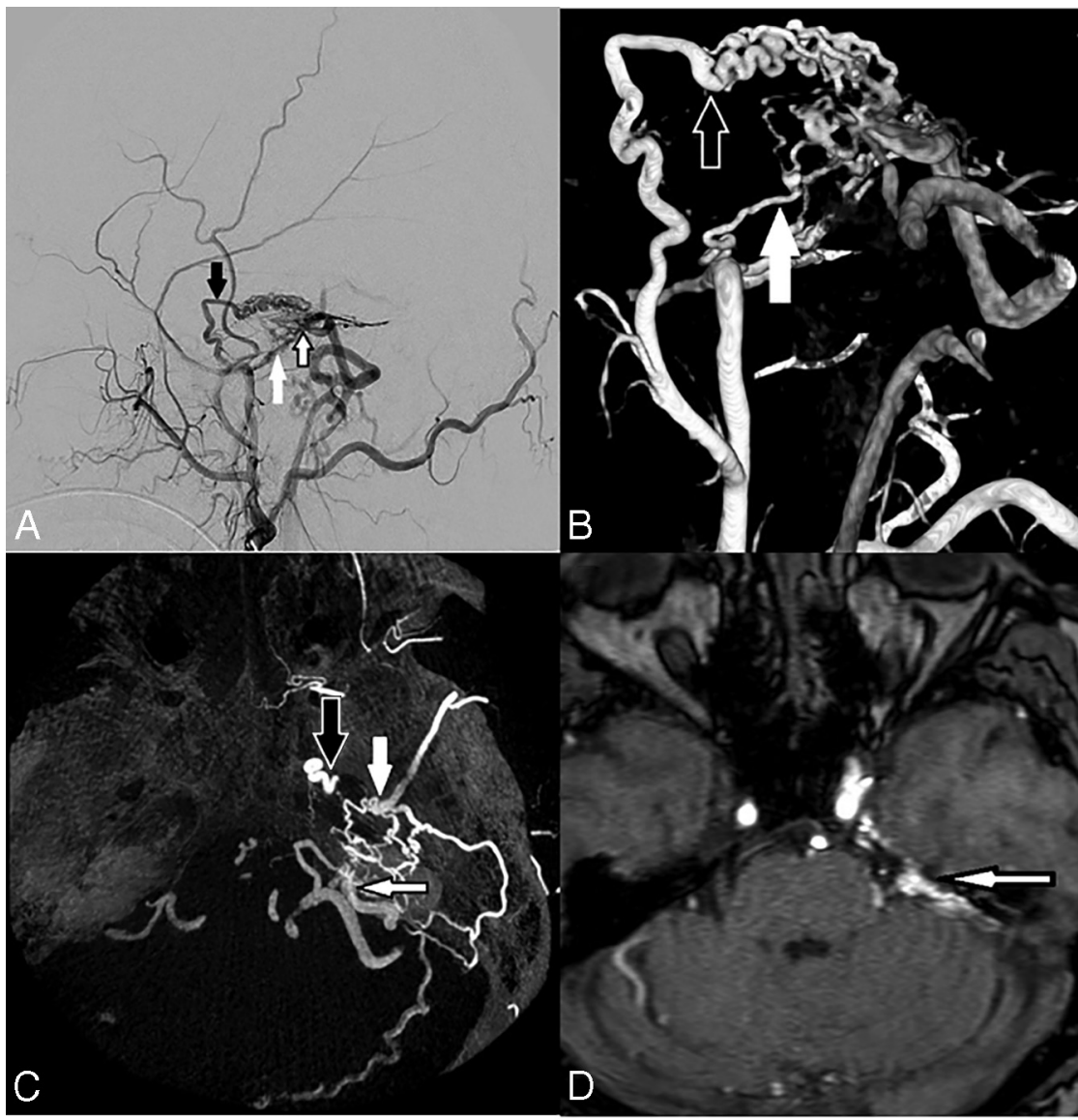

FIG 3. Angiographic assessment of a left petrous dAVF. A, Lateral projection DSA of a left ECA injection shows arterial supply to the AVF by the petrous branch of the middle meningeal artery (white arrow), a component of the facial nerve arterial arcade, by the accessory meningeal artery (black arrow) with an intervening nidus before the venous drainage and the fistula draining into the petrosal vein (black-border arrow) over the posterior superior surface of the left petrous temporal bone. $B, 3 D$ rotational DSA via a left ECA injection in the lateral projection reconstruction again shows the petrous branch of the left middle meningeal artery (white arrow) and the accessory meningeal artery (white border arrow) entering a nidal network before the fistulous point. C, Reconstructed axial MPR MIP image of a 3D rotational DSA via a left ECA injection demonstrates, in exquisite anatomic detail, the petrous branch of the left middle meningeal artery extending posteriorly from the foramen spinosum over the petrous temporal bone (white arrow), accessory meningeal artery entering via foramen ovale (black arrow), and the draining petrosal vein (black border arrow). This level of anatomic detail and spatial relationship to the skull base foramina is difficult to appreciate on standard DSA images, and this allows assessment of the potential risks of facial nerve ischemia that may be associated with a transarterial approach. $D$, Axial TOF-MRA image demonstrates pathologic hyperintense signal in the left petrosal vein (black border arrow) due to pre-excited protons entering via the high-flow left petrosal dAVF. $A-C$, Reproduced from the supplemental material of Bhatia et al. ${ }^{41}$

approach). These risks are discussed in detail in the second article of this series focused on TA embolization.

4. Risk from a transvenous (TV) embolization approach: Based on the venous drainage pattern, we determine the risk of intracranial hemorrhage, venous infarction, or long-term intracranial venous hypertension that would be associated with a TV embolization approach (eg, in a patient with a single/dominant transverse sinus, coil occlusion of that sinus for treatment of an AVF may pose a long-term risk of venous hypertension). These risks are discussed in detail in the third article of this series focused on TV embolization.
Multidisciplinary Discussion. We discuss all new AVF cases at our monthly multidisciplinary neurovascular meeting, attended by interventional neuroradiologists, cerebrovascular surgeons, vascular neurologists, and gamma knife radiosurgeons. In emergent cases requiring more rapid decision-making (eg, clinical presentation with intracranial hemorrhage or progressive nonhemorrhagic neurologic deficits), the management discussion is undertaken acutely among the admitting cerebrovascular surgeon, the on-call interventional neuroradiologist, and, when appropriate (eg, presentation with seizures), the treating vascular neurologist. The advantages of multidisciplinary discussion include the potential range of management options that can be considered as well as engagement of all relevant specialties early in the treatment course.

Decision to Offer Interventional Treatment. The first and most important decision made during the multidisciplinary discussion is whether the patient requires interventional treatment of the AVF or conservative management with clinical and imaging follow-up. This decision is based primarily on the venous drainage pattern and the associated natural history, ie, whether the AVF has a benign or aggressive venous drainage pattern. All patients with aggressive venous drainage patterns should be offered treatment because of the poor natural history.

In patients with benign drainage patterns, interventional treatment may still be offered if the symptoms cause significant functional disability and the patient is willing to accept the risks of intervention to reduce that disability (eg, severe pulsatile tinnitus can interfere with sleep and quality of life, in some cases contributing to mood disorders and even suicide). For patients with benign drainage patterns and tolerable symptoms, we recommend conservative management with annual clinical and imaging follow-up (because benign drainage patterns can transform into aggressive patterns with time in approximately $2 \%-4 \%$ of patients). $2,8,13,20$

The major risk factor for conversion from benign to aggressive drainage is spontaneous thrombosis of the ipsilateral draining vein, which may be heralded by a change (increase or decrease) in the patient's symptoms. ${ }^{2,13,20}$ Such change in symptoms warrants 
earlier follow-up and imaging. ${ }^{2}$ In our practice, we use contrastenhanced time-resolved MR angiography for follow-up of conservatively managed patients because it allows noninvasive assessment of the intracranial circulation in multiple phases and has a high sensitivity for detecting aggressive venous drainage patterns. ${ }^{36,42}$ In patients with contraindications for MR imaging, 4D CTA is also an option to avoid repeat invasive DSAs. ${ }^{37}$

Treatment Options. For patients in whom interventional treatment is indicated, 4 major treatment options are available:

1. TA embolization

2. TV embolization

3. Microsurgical disconnection

4. Gamma knife radiosurgery (GKRS).

Endovascular Approaches. At our institution, we have adopted an endovascular-first approach to treating intracranial AVFs when possible, based on improving angiographic and clinical cure rates because technology and strategies have evolved in the past 2 decades. ${ }^{43}$ A major technologic advancement was the development of modern liquid embolic agents (in particular, ethylene-vinyl alcohol copolymer) that allow embolization in a more controlled fashion than ethanol or glue, resulting in higher angiographic cure rates. ${ }^{43,44}$ The use of these agents has resulted in modified endovascular treatment strategies, in which plug formation, dual microcatheter techniques (pressure cooker), or flow arrest via a dual-lumen balloon are used to allow antegrade (for TA approaches) or retrograde (for TV approaches) controlled advancement of the embolic agent to occlude the fistulous point. ${ }^{44-47}$

Detailed descriptions of the techniques used during TA and TV embolization are provided in the second and third articles of this series.

Microsurgical Disconnection. In cases in which the estimated risks associated with TA and/or TV embolization are elevated, microsurgical disconnection is an effective treatment option. In this setting, multidisciplinary discussion is particularly useful to weigh the risks and benefits of endovascular-versus-surgical approaches. We have frequently encountered cases in which the endovascular approach is difficult and associated with a high risk of cranial nerve palsy or stroke, while being a relatively simple case for microsurgical disconnection (eg, petrous AVFs involving the facial nerve arterial arcade or anterior cranial fossa AVFs supplied by ethmoidal branches of the ophthalmic artery). The surgical goal is to disconnect the draining vein of the AVF using aneurysm clips or ligation. ${ }^{48}$ Even if achieving this surgical goal does not result in angiographic cure, it will usually result in disconnection of the dangerous aspect of the AVF, the cortical venous reflux, thus converting an aggressive AVF into a benign one. $^{19,48}$

However, the invasive nature of open surgical approaches is associated with potential complications that are often avoided by endovascular approaches, such as CSF leak, pseudomeningocele formation, hydrocephalus, infection, and wound pain. ${ }^{14,19}$ In addition, the tissue disruption associated with an operation is a potential trigger for further dAVF development. A strong working relationship between interventional neuroradiologists and cerebrovascular surgeons is useful in selecting the most appropriate treatment approach for any given AVF, to minimize the risk of complications from either an endovascular or open surgical approach.

GKRS. GKRS, while being an effective treatment option for parenchymal AVMs, has a more limited role in the treatment of dAVFs. In our experience, the long-term outcomes after GKRS for dAVFs are suboptimal (50\% angiographic cure rate), and some patients require further treatment via 1 of the 3 main modalities above. ${ }^{49}$ GKRS is a useful alternative for symptom palliation in patients who have failed other treatments or are averse to endovascular/surgical intervention. ${ }^{43,49}$ An example of the utility of GKRS is reducing the severity of pulsatile tinnitus in patients with incurable or recurrent transverse sinus AVFs. ${ }^{49}$

\section{CONCLUSIONS}

Intracranial dAVFs are stratified by the absence or presence of cortical venous reflux. These lesions are best managed using the principles of detailed angiographic anatomic assessment and multidisciplinary discussion. We detail TA and TV embolization techniques in our next 2 articles.

Disclosures: Timo Krings-UNRELATED: Consultancy: Stryker, Penumbra, Medtronic, Cerenovus Royalties: Thieme; Stock/Stock Options: Marblehead.

\section{REFERENCES}

1. Newton TH, Cronqvist S. Involvement of dural arteries in intracranial arteriovenous malformations. Radiology 1969;93:1071-78 CrossRef Medline

2. Cognard C, Gobin YP, Pierot L, et al. Cerebral dural arteriovenous fistulas: clinical and angiographic correlation with a revised classification of venous drainage. Radiology 1995;194:671-80 CrossRef Medline

3. Borden JA, Wu JK, Shucart WA. A proposed classification for spinal and cranial dural arteriovenous fistulous malformations and implications for treatment. J Neurosurg 1995;82:166-79 CrossRef Medline

4. Osada T, Krings T. Intracranial dural arteriovenous fistulas with pial arterial supply. Neurosurgery 2019;84:104-15 CrossRef Medline

5. Weinstein M, Stein R, Pollock J, et al. Meningeal branch of the posterior cerebral artery. Neuroradiology 1974;7:129-31 CrossRef Medline

6. Wollschlaeger PB, Wollschlaeger G. An infratentorial meningeal artery [in German]. Radiologe 1965;5:451-52 Medline

7. Bhatia KD, Kortman H, Walchli T, et al. Artery of Davidoff and Schechter supply in dural arteriovenous fistulas. AJNR Am J Neuroradiol 2020;41:300-04 CrossRef Medline

8. Gross BA, Du R. The natural history of cerebral dural arteriovenous fistulae. Neurosurgery 2012;71:594-602; discussion 602-03 CrossRef Medline

9. Al-Shahi R, Bhattacharya JJ, Currie DG, et al; Scottish Intracranial Vascular Malformation Study Collaborators. Prospective, population-based detection of intracranial vascular malformations in adults: the Scottish Intracranial Vascular Malformation Study (SIVMS). Stroke 2003;34:1163-69 CrossRef Medline

10. Kuwayama N. Epidemiologic survey of dural arteriovenous fistulas in Japan: clinical frequency and present status of treatment. Acta Neurochir Suppl 2016;123:185-88 CrossRef Medline

11. Piippo A, Niemela M, van Popta J, et al. Characteristics and longterm outcome of 251 patients with dural arteriovenous fistulas in a defined population. J Neurosurg 2013;118:923-34 CrossRef Medline 
12. Hiramatsu M, Sugiu K, Hishikawa T, et al. Epidemiology of dural arteriovenous fistula in Japan: analysis of Japanese Registry of Neuroendovascular Therapy (JR-NET2). Neurol Med Chir (Tokyo) 2014;54:63-71 CrossRef Medline

13. Elhammady MS, Ambekar S, Heros RC. Epidemiology, clinical presentation, diagnostic evaluation, and prognosis of cerebral dural arteriovenous fistulas. Handb Clin Neurol 2017;143:99-105 CrossRef Medline

14. Hiramatsu M, Sugiu K, Hishikawa T, et al. Results of 1940 embolizations for dural arteriovenous fistulas: Japanese Registry of Neuroendovascular Therapy (JR-NET3). J Neurosurg 2019 June 28. [Epub ahead of print] CrossRef Medline

15. Lasjaunias P, Berenstein A, terBrugge K. Surgical Neuroangiography: Vol.2: Clinical and Endovascular Treatment Aspects in Adults. 2nd ed. Springer-Verlag; 2004

16. Houser OW, Campbell JK, Campbell RJ, et al. Arteriovenous malformation affecting the transverse dural venous sinus-an acquired lesion. Mayo Clin Proc 1979;54:651-61 Medline

17. Lawton MT, Jacobowitz R, Spetzler RF. Redefined role of angiogenesis in the pathogenesis of dural arteriovenous malformations. $J$ Neurosurg 1997;87:267-74 CrossRef Medline

18. Geibprasert S, Pereira V, Krings T, et al. Dural arteriovenous shunts: a new classification of craniospinal epidural venous anatomical bases and clinical correlations. Stroke 2008;39:2783-94 CrossRef Medline

19. Lawton MT, Sanchez-Mejia RO, Pham D, et al. Tentorial dural arteriovenous fistulae: operative strategies and microsurgical results for six types. Neurosurgery 2008;62:110-24; discussion 124-25 CrossRef Medline

20. Gross BA, Albuquerque FC, Moon K, et al. Evolution of treatment and a detailed analysis of occlusion, recurrence, and clinical outcomes in an endovascular library of $\mathbf{2 6 0}$ dural arteriovenous fistulas. J Neurosurg 2017;126:1884-93 CrossRef Medline

21. van Dijk JM, terBrugge KG, Willinsky RA, et al. Clinical course of cranial dural arteriovenous fistulas with long-term persistent cortical venous reflux. Stroke 2002;33:1233-36 CrossRef Medline

22. Duffau H, Lopes M, Janosevic V, et al. Early rebleeding from intracranial dural arteriovenous fistulas: report of 20 cases and review of the literature. J Neurosurg 1999;90:78-84 CrossRef Medline

23. Miller TR, Serulle Y, Gandhi D. Arterial abnormalities leading to tinnitus. Neuroimaging Clin N Am 2016;26:227-36 CrossRef Medline

24. Miller NR. Diagnosis and management of dural carotid-cavernous sinus fistulas. Neurosurg Focus 2007;23:E13 CrossRef Medline

25. Brito A, Tsang AC, Hilditch $\mathrm{C}$, et al. Intracranial dural arteriovenous fistula as a reversible cause of dementia: case series and literature review. World Neurosurg 2019;121:e543-53 CrossRef Medline

26. Letourneau-Guillon L, Cruz JP, Krings T. CT and MR imaging of non-cavernous cranial dural arteriovenous fistulas: findings associated with cortical venous reflux. Eur J Radiol 2015;84:1555-63 CrossRef Medline

27. Alatakis S, Koulouris G, Stuckey S. CT-demonstrated transcalvarial channels diagnostic of dural arteriovenous fistula. AJNR Am J Neuroradiol 2005;26:2393-96 Medline

28. Heit JJ, Iv M, Wintermark M. Imaging of intracranial hemorrhage. J Stroke 2017;19:11-27 CrossRef Medline

29. Snyder VS, Chen JY, Hansen LA. Ruptured dural arteriovenous fistula/malformation. Acad Forensic Pathol 2017;7:299-311 CrossRef Medline

30. Hernandez-Diaz ZM, Llibre-Guerra JC, Arteche-Prior M, et al. Spontaneous subdural hematoma and behavioral changes due to a dural arteriovenous fistula. A case report and literature review. Behav Sci (Basel) 2019;9:63 CrossRef Medline
31. Azuma M, Hirai T, Shigematsu Y, et al. Evaluation of intracranial dural arteriovenous fistulas: comparison of unenhanced 3T 3D time-of-flight MR angiography with digital subtraction angiography. Mag Reson Med Sci 2015;14:285-93 CrossRef Medline

32. Kwon BJ, Han MH, Kang HS, et al. MR imaging findings of intracranial dural arteriovenous fistulas: relations with venous drainage patterns. AJNR Am J Neuroradiol 2005;26:2500-07 Medline

33. Wilcock DJ, Jaspan T, Worthington BS. Problems and pitfalls of 3-D TOF magnetic resonance angiography of the intracranial circulation. Clin Radiol 1995;50:526-32 CrossRef Medline

34. Grossberg JA, Howard BM, Saindane AM. The use of contrastenhanced, time-resolved magnetic resonance angiography in cerebrovascular pathology. Neurosurg Focus 2019;47:E3 CrossRef Medline

35. Chen CC, Chang PC, Shy CG, et al. CT angiography and MR angiography in the evaluation of carotid cavernous sinus fistula prior to embolization: a comparison of techniques. AJNR Am J Neuroradiol 2005;26:2349-56 Medline

36. Farb RI, Agid R, Willinsky RA, et al. Cranial dural arteriovenous fistula: diagnosis and classification with time-resolved MR angiography at 3T. AJNR Am J Neuroradiol 2009;30:1546-51 CrossRef Medline

37. In 't Veld M, Fronczek R, Dos Santos MP, et al. High sensitivity and specificity of $4 \mathrm{D}$-CTA in the detection of cranial arteriovenous shunts. Eur Radiol 2019;29:5961-70 CrossRef Medline

38. Serulle Y, Miller TR, Gandhi D. Dural arteriovenous fistulae: imaging and management. Neuroimaging Clin N Am 2016;26:247-58 CrossRef Medline

39. Botsford A, Shankar JJS. Digital subtraction angiography-Dynavision in pretreatment planning for embolization of dural arterio-venous fistulas. J Neuroimaging 2018;28:112-17 CrossRef Medline

40. Eesa M, Sharma P, Mitha AP, et al. Angiographic computed tomography with selective microcatheterization in delineating surgical anatomy in the case of a dural arteriovenous fistula: technical note. J Neurosurg 2009;111:916-18 CrossRef Medline

41. Bhatia $\mathrm{KD}$, Kortman $\mathrm{H}$, Lee $\mathrm{H}$, et al. Facial nerve arterial arcade supply in dural arteriovenous fistulas: anatomy and treatment strategies. AJNR Am J Neuroradiol 2020;41:687-92 CrossRef Medline

42. Reinacher PC, Stracke P, Reinges MH, et al. Contrast-enhanced time-resolved 3-D MRA: applications in neurosurgery and interventional neuroradiology. Neuroradiology 2007;49(Suppl 1):S3-13 CrossRef Medline

43. Signorelli F, Gory B, Maduri R, et al. Intracranial dural arteriovenous fistulas: a review of their current management based on emerging knowledge. J Neurosurg Sci 2017;61:193-206 CrossRef Medline

44. Mantilla D, Le Corre M, Cagnazzo F, et al. Outcome of transarterial treatment of dural arteriovenous fistulas with direct or indirect cortical venous drainage. J Neurointerv Surg 2018;10:958-63 CrossRef Medline

45. Chapot R, Stracke P, Velasco A, et al. The pressure cooker technique for the treatment of brain AVMs. J Neuroradiol 2014;41:87-91 CrossRef Medline

46. Zhang G, Zhu S, Wu P, et al. The transvenous pressure cooker technique: a treatment for brain arteriovenous malformations. Interv Neuroradiol 2017;23:194-99 CrossRef Medline

47. Dabus G, Linfante I, Martínez-Galdámez M. Endovascular treatment of dural arteriovenous fistulas using dual lumen balloon microcatheter: technical aspects and results. Clin Neurol Neurosurg 2014;117:22-27 CrossRef Medline

48. Radovanovic I, Wallace M. Cranial dural arterovenous fistula disconnection. In: Jandial R, McCormick P, Black P, eds. Core Techniques in Operative Neurosurgery. Elsevier; 2019

49. Dmytriw AA, Schwartz ML, Cusimano MD, et al. Gamma knife radiosurgery for the treatment of intracranial dural arteriovenous fistulas. Interv Neuroradiol 2017;23:211-20 CrossRef Medline 